\section{Cell adhesion molecules in enteropathic processes}

\section{Hill S M., Milla P J., Caseseca T., Mirakian R.}

Dept. of Child Health, Institute of Child Health and Dept. of Immunology University College \& Middlesex School of Medicine. The inmune respont is to $T$ lymphocytes, and specific "accessory" molecules are moleculos pred of allow effective cell also expressed on the surfaces or the cellular adhesion molecule 1 (ICAM-1) adhesion. Tho such mocules ar lymohocyte function detected on antigen presenting cells which acts as a ligand for leshocyte nnct associated antigen 1 ( $L F A-1$ ) found on leucocytes. In Coeliac Disease (CD) and autoirmune enteropathy (AIE) aberrant class II/DR expression occurs on je jural crypt enterocytes. Wh have previously suggested that in AIE altered antigen presentation initiates and/or perpetuates the enteropathic process. We now investigate whether altered adhesion molecule expression plays a role in this process. Je jun logiallat corpored. Cryostat section logically nomal mucosa and nom monoclonal antiwere stained by an indirect im bodies to ICM by crypt enterocytes was present. ICM-1 was $F^{2} 1$ were neptive in $C D$ and control

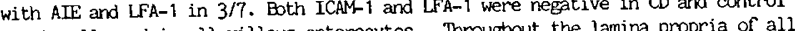
crypt cells and in all villous enterocytes. Thoughout the lan ina propria of all biopsies LFA-1 and ICAM-1 +ve cells were detected but in greater numbers with more intense staining in AIE. Thus in AIE but not CD aberrant Dh expression correlates with enhanced and inappropriate epithelial cell adhesion molecule express perpetuate the enteropathic process.

\section{Congenital chloridorrhoea (CCD) without diarrhoea!}

12 Milla P J., Bisset W M., Sanderson I., Jenkins H R.

Hospitals for Sick Qhildren and Institute of Child Health, London.

Congenital chloridorrhoea is an inherited life threatening disorder usually with profuse watery diarrhoea which starts in utero. The diarrhoea is characterised by large volumes of chloride rich watery stools due to defective anion exchange transporters in the ileum and colon. We have investigated $\mathrm{C}$ - transport in the colon using non-equilibrium rectal dialysis in children with $C C D$ and controls. 2 Caucasians had classic CCD with diarrhoea from birth (GPA.) but 4, 3 from the Arabian Gulf and 1 from Nigeria presented with marked hypochloreamia $(21-77 \mathrm{~mol} / 1)$, hypokalaemia, severe failure to thrive and unusually passed formed stools (GpB). Because of this feature diamosis was delayed in B and in 2/4 an erroneous diagnosis of Bartters syndrome was made. All four in B had marked secondary hyperaldosteronism plasma aldosterone $590->3300$ pmol/1 $\mathrm{nr}$ 96-946; plasma renin 4300 aldosteronism plasma aldosterone $9530 \mathrm{Al} / \mathrm{L} / \mathrm{hr} \mathrm{nr}$ 110-2610; rectal potential differences (PD) 82-100 mv nr 25-40. to $9530 \mathrm{Al} / \mathrm{L} / \mathrm{hr} n \mathrm{nr} / 10-26 \mathrm{~d}$; rectal potential drolyte deficit in B profuse watery diarrhoea developed with stool chlorides of $124-153 \mathrm{~mol} / 1$ which exceeded the sum diarrhoea developed with stool chlorides of $124-153 \mathrm{~mol} / 1$ which exceeded the sum
of $\mathrm{Na}+$ and $\mathrm{K}+$ conc $\mathrm{c}^{2}$. In A using a dialysate of $130 \mathrm{mM} \mathrm{CL}^{-}, \mathrm{CL}^{-}$secretion of -70 and $-32 \mathrm{mmol} / \mathrm{min} / \mathrm{cm}^{2}$ was seen compared to absorption in controls $(n=17)+195+55$ mean $+1 \mathrm{SD}$ and $\mathrm{B}+26-+69$. In 1 of $\mathrm{B}$ the effects of varying the $\mathrm{CL}^{-}$concentration of the incubation solution on $\mathrm{CL}^{-}$fluxes was determined. $130 \mathrm{mM}+69,90 \mathrm{mM}-69,60 \mathrm{mM}-107$, $30 \mathrm{mM}-223 \mathrm{~mol} / \mathrm{min} / \mathrm{cm}^{2}$. These data suggest that $\mathrm{CL}^{-}$is moving passively down a chemical gradient whereas in A active secretion occurs. As diarrhoea in CCD is due che the to the osmotic effect of luminal $C^{2}$ when $C L$ depletion is present it may and these
DESCRIPTION OF A PUTATIVE ENTEROTOXIN PRODUCED BY

ENTEROAGGREATIVE ESCHFRICHIA COLI (EAggEC).

S.J.Savarino, A.Fasano, D.C.Robertson, M.M.Levine

AAgEC have been associated with persistent diarrhea in children, yet litrle is known about virulence factors. Aim. We assayed for enterotoxic activity in culture filtrates(CF) of EAggEC strains Methods. CF from 17-2 (a prototype Chilean EAggEC), 8 other EAggEC strains and E. coli HBI0l were added to stripped rabbit cested by E. coli STa ELISA and suckling mouse assay (SMA). EAggEC colonies were hybridized under low stringency to STh and STP DNA probes. Resu1ts. Addition of 17-2 CF to the RIM in UCs caused a greater rise in short circuit current $(\Delta 1 \mathrm{sc}=55.2 \pm 5.3$ uAmp $/ \mathrm{cm} 2$ ) (Mean $\mathrm{sE}$ ) than $\pm 3.0 \mathrm{uAmp} / \mathrm{cm} 2)(\mathrm{p}<0.001)$. This activity on Isc was 1$) 65 \%$ stable after heating ( $15 \mathrm{~m}$ at $\left.65^{\circ} \mathrm{C}\right) ; 2$ ) localized to the $2-5 \mathrm{kDa}$ MW size range; and 3) reproduced with CF from $\mathrm{HB} 101$ transformed with $17-2$ plasmid. Compared to $\Delta \mathrm{Isc}$ response to $8-\mathrm{Br}-\mathrm{cGMP}$ on negative con-
trol tissue $(\Delta \mathrm{Isc}=123.4 \pm 7.9 \mathrm{uAmp} / \mathrm{cm} 2)$, the $\Delta \mathrm{Isc}$ to $8-\mathrm{Br}-\mathrm{cGMP}$

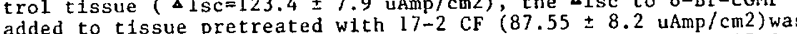
added to tissue pretricantly less $(p<0.01)$, while the additive effect of $17-2$ $\mathrm{SF}$ and $8-\mathrm{Br}-\mathrm{cGMP}(\mathrm{I} \mathrm{ISC}=142.8 \pm 9.1 \mathrm{uAmp} / \mathrm{cm} 2)$ was not significantly $\mathrm{CF}$ and $8-\mathrm{Br}-\mathrm{cGMP}(\Delta \mathrm{IsC}=142.8 \pm 9$.1 uAmp/cm2) was not significant
different $(\mathrm{p}>0.05)$. <10 $\mathrm{kDa} \mathrm{CF}$ fractions from $6 / 8$ other EAggEC strains screened in UCs gave AIsc responses similar to $17-2$. The 17-2 CF activity was 1) non-neutralizable with polyclonal anti-STa in UCs; 2) non-reactive by STa ELISA; and 3) negative in SMA. Also, EAggEC colonies did not hybridize with STh or STp DNA probes. partialiy heat stable moiety which gives an electrical respons in vitro consistent with an enterotoxic effect. This putative FAggC heat stable enterotoxin (EAST) appears to be plasmid-mediated, not genetically or ímmunologically cross-reactive with E. coli STa, and may act via cGMP as intracellular mediator. \begin{abstract}
these may determine the presenting features.
\end{abstract}
PRODUCTION OF A SECOND DIARRHEAGENIC FACTOR BX $\underline{\mathrm{v}}$.

15 CHOLERAE.

A. Fasano, B. Baudry, D. W. $\vec{B} \cdot$ Kaper. U. UD Sch. Med., Baltimore, $\frac{\text { MD }}{21} 20$, U.S.A. In the last decade a great effort has been made to produce an efficient vaccine against cholera. When fed to volunteers, some genetically engineered mutants lacking the cholera toxin(CT)genes (CVD 101) induced mild diarrhea(1), while others $(395 \mathrm{Nl})$ did not (2). Aim of the present study was to evaluate whether toxic factors other than CT are involved in the pathogenesis of cholera. Methods:crude culture supernatants from $v$. cholerae 395 and from two similarly conture supernatants from tine stripped of serosal and muscular layers and mounted in Ussing chambers. At the end of the experiments,tissues were processed for electron microscopy. Results:a) 395 and CVD101 supernatants added to electron microscopy. Resuline gave a significant increase in tisthe mucosa of small intinctance $(\mathrm{Gt})$ peaking after $2 \mathrm{hrs}$. This increase caused an early increase in short circuit current(Isc) that was not related to CT activity. No change in Gt was observed when 395 supernatant was added to the caecal tissue;b) 395N did not increase $\mathrm{Ct}$ for 100 min. when added to the small intestine;c)preliminary freeze-fracture data showed that tight-junctions $(t j)$ became less complex, having fewer intersections, in tissues exposed to 395 or CVDl01 supernatants, compared to those exposed to medium alone.Conclusions: 1) 395 and CVD101 supernatants induced a signiffeat incric CT-mutant) did not. Exposing caecum to 395 did not alter Gt;2) the Gt increase was associated with morphological changes of $t j ; 3$ ) this factor may be responsible for the residual diarrhea observed in some CT-

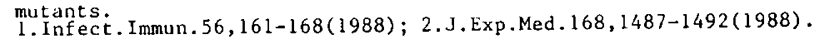

\section{6}

IN SITU HYBRIDIZATION FOR DETECTION OF HEPATITIS B VIDUREN S. Wirth, A. Hueter, K.M. Keller, W. Baumann, B. Zabel Children's Hospital, Johannes Gutenberg-University, D-6500 Mainz Detection of hepatitis B virus (HBV)-DNA in the liver of chronic infected patients is presently the most sensitive marker of viral replication and infectivity. In silu hybridization (ISH) allows replication and infectivity. InV infected liver cells and distrithe direct visualization of HBV infected liver cells and distribution of the viral sequences. This study was done to establish
ISH and correlate the findings with conventional markers for HBV infection.

Methods. Liver biopsies of 50 patients (28 o, 22 \%) aged $0.5-20$ years (mean 10.3) with various histological diagnoses were tested by ISH. The HBV-DNA probe was labeled by nick translation with ${ }_{3} \mathrm{~S}$ S-CTP to a specific activity of $3-5 \times 10^{8} \mathrm{cpm} / \mu \mathrm{g}$ DNA.

Results. HBV-DNA/mRNA could be demonstrated in 38 patients, 12 were negative. Distribution of the grains was homogenous, inhomogenous with focal patches and focal. $33 / 38$ children with llBeAg genous with focal and $4 / 11$ with anti-HBe were positive by $1 \mathrm{SH}, 5 / 38$ with HBeAg and
$7 / 11$ with anti-HBe remained negative. $17 / 23 \mathrm{HBsAg}$ carriers with positive HBV-DNA/mRNA by ISH were positive for lIBCAg in the liver and $31 / 36$ had free HBV-DNA in Southern blot hybridization. Conclusions. Our results indicate that hepatitis B viral genomes can reliably be detected by in situ hybridization. Although there is a good correlation to other HBV markers (HBeAg $\mathrm{HBCAg}$ and Southern blot hybridization) ISH may represent a more sensilive method to prove viral replication and infectivity. 